\title{
EL PESO de LA ÉTICA EN LA POLÍtica
}

DAVID ALVARGONZÁLEZ

Universidad de Oviedo

RESUMEN: Las relaciones entre los principios de la ética y los requerimientos de la política no siempre son armónicas. En este artículo, en primer lugar, se propone una definición de los ámbitos propios de la ética y de la política. A continuación, se analizan dos ámbitos en los que se aprecia un conflicto inevitable, estructural, entre ética y política de modo que el bien político requiere el mal ético: los conflictos armados y las políticas de inmigración. A continuación, se hace referencia a conflictos que pretenden estar justificados en la idiosincrasia histórica o cultural de ciertas naciones. Por último, se citan contextos donde la ética y la política persiguen fines comunes o, simplemente, se ignoran mutuamente.

PALABRAS CLAVE: ética; política; Estado; guerra; inmigración.

\section{The influence of ethics on politics}

ABSTRACT: The relationships between ethical principles and political requirements have proven to be controversial. In this paper, firstly I will propose a definition of ethics and politics. Then, I will analyze two illustrations of the unavoidable structural conflict between ethics and politics: wars and immigration policies. In those cases political goods require ethical evils. Then, I will refer to conflicts which claim to be rooted on the cultural and historical idiosyncrasies of certain nations. Finally, I will refer to several situations in which ethics and politics share common objectives and other ones in which they just follow independent courses.

KEY WORDS: ethics; politics; State; war; immigration.

\section{INTRODUCCIÓN}

El tema de este artículo, el análisis de las relaciones entre los principios o normas éticas y los requerimientos de la política, es un asunto muy controvertido y sujeto a muchas valoraciones. Ahora bien, con el fin de poder tratar este problema con la serenidad que merece, mi propósito aquí va a ser el de evitar, en todo momento, las referencias más próximas para poder tratar el asunto de un modo abstracto, filosófico y, en la medida de lo posible, presentar lo que sería la estructura de un problema objetivo. La tradición en la que yo quisiera inscribir mi análisis en esta lección es la que reivindica Spinoza cuando, en su Tratado político, dice:

Y, a fin de investigar todo lo relativo a esta ciencia [se refiere Spinoza a la política] con la misma libertad de espíritu con que solemos tratar los temas matemáticos, me he esmerado en no ridiculizar ni lamentar ni detestar las acciones humanas, sino en entenderlas. Yo por eso he contemplado los afectos humanos como son el amor, el odio, la ira, la envidia, la gloria, la misericordia y las demás afecciones del alma, no como vicios de la naturaleza humana, sino como propiedades que le pertenecen como el calor, el frío, la tempestad, el trueno y otras cosas por el estilo le pertenecen a la naturaleza de aire. $[\ldots]^{1}$

$1 \quad$ SpINOZA, B., Tratado político, I, §4. 
Atendiendo estas indicaciones, en lo que sigue tan solo haré una propuesta de lo que se puede entender por ética y por política para poder analizar algunas situaciones prácticas existentes que ilustran su relación mutua, tanto cuando ésta es armónica como, sobre todo, cuando resulta conflictiva.

\section{Presentación de las definiciones de Ética y política Que SE VAN a Utilizar}

Como es común cuando tratamos de ideas filosóficas, hay muchas maneras posibles y diferentes de definir la ética y la política. Yo voy a pedir al lector que, a lo largo de este artículo, me acompañe en un determinado modo de entenderlas que se inscribe en una tradición ampliamente ejercitada en la historia de la filosofía. Esta tradición arranca de la Ética a Nicómaco, la Ética a Eudemo y la Política de Aristóteles y es seguida por Spinoza en su famosa Ética, en su Tratado político y en su Tratado teológico-político. Entre nosotros, Gustavo Bueno ha formulado con especial claridad los diferentes usos de estos términos y ha propuesto unas ideas y unas definiciones que tomaré aquí como referencia².

Hay muchas maneras de entender la Ética. En los países de habla hispana, la manera usual viene siendo la de considerar la Ética como el «tratado de la moral»: así como se distingue el terreno frente a la Geografía, que sería la disciplina que estudia el terreno, así también se distinguiría entre las normas morales dadas de un modo empírico (social, histórico) y la Ética, que sería la disciplina académica encargada de estudiar esas normas. Yo voy a separarme aquí de esa tradición, por otra parte tan justificada y tan consolidada académicamente entre nosotros. Siguiendo en esto también a Spinoza, entenderé la ética como el conjunto de normas que tienen que ver directamente con la "perseverancia en el ser» del individuo corpóreo humano que es también, en la situación canónica, una persona. Todo aquello que contribuye a la fortaleza y la firmeza del sujeto humano individual corpóreo será considerado ético: así, por ejemplo, todos los comportamientos dirigidos a conservar su salud, y a lograr su correcto desarrollo serán considerados «éticos». Por consiguiente, la fortaleza y la firmeza serían las virtudes éticas cardinales. Todas las personas integradas en una cultura tienen un conocimiento práctico mundano de las normas que contribuyen a su firmeza y a la generosidad con los demás, con independencia de que desconozcan la Ética académica, del mismo modo que son capaces de hablar su lengua materna sin tener una representación explícita de las reglas de su gramática. Según este modo de entender la ética ligada a la preservación y la buena marcha del sujeto, la medicina será, estructuralmente, una disciplina ética pues trata de hacer que el individuo corpóreo enfermo se transforme en sano, devolviéndole la firmeza que la enfermedad socaba; la educación también sería en muchos casos una actividad ética pues trataría de ayudar a crecer de un modo recto al individuo y

2 Bueno, G., «Lectura primera: Ética y moral y derecho», en: Bueno, G., El sentido de la vida, seis lecturas de filosofía moral. Oviedo: Pentalfa, 1996. http://fgbueno.es/med/dig/ gb96sv1.pdf

Bueno, G., «En nombre de la ética», El Catoblepas. Revista crítica del presente, 16 (jun 2003): 2. http://nodulo.org/ec/2003/n016p02.htm 
de constituirlo como persona permitiendo que desarrolle sus aptitudes, ayudándole a constituir su propia firmeza y fortaleza. Al contrario, todo lo que atenta contra el sujeto corpóreo individual y contra la persona será anti-ético: el asesinato, el homicidio, la esclavitud, la mutilación, la violación, el abuso, la tortura, los daños físicos, la difamación, la denigración, el escarnio, la extorsión, el acoso, etc. Del mismo modo, toda acción que el individuo realice en su propio perjuicio, como pueda ser, en el límite, el suicidio, pero también el abuso de drogas o de alcohol, o los hábitos alimenticios perniciosos, será también una acción antiética de acuerdo con el criterio que estoy defendiendo aquí.

La ética, vista desde esta perspectiva toma en consideración un sujeto humano abstracto con independencia de su raza, su lengua, su religión, su sexo, y su edad. Todos los individuos están sujetos a esas normas éticas (contra el homicidio, la violación, la mutilación, etc.) con independencia de su etnia, sexo, religión, edad, o lengua. Las razas, las lenguas, y todo lo demás se consideran ecualizadas en un sujeto humano individual genérico, abstracto, distributivo. Ese sujeto sin religión ni raza, ni sexo, ni edad no existe como sujeto empírico, como individuo de carne y hueso, sino que sólo existe como sujeto abstracto porque la perspectiva ética pasa por encima de esas determinaciones concretas del individuo. Podríamos decir que ese individuo abstracto se parece al dado equi-probable de los matemáticos que, aunque no existe como dado empírico, sí existe como construcción abstracta matemática resultado de lanzar un mismo dado un gran número de veces.

Por lo que se refiere a la política, voy a distinguir dos usos de la palabra política: uno amplio y otro más restringido. En un sentido amplio, se habla de política en contextos muy diversos como cuando se hace referencia a la política de un equipo de futbol o de una empresa. Frans de Waal llegó a hablar incluso de la política de los chimpancés, refiriéndose a las relaciones de poder dentro de un grupo de chimpancés del zoo de Harnhem en Holanda ${ }^{3}$. Este es el uso amplio, laxo, reconocido en muchos idiomas modernos de nuestro entorno. En su uso restringido o estricto, el término "política" se refiere a todo aquello que tiene que ver con el Estado. El Estado es una institución histórica que tiene sus orígenes allí donde los pone en cada momento la investigación arqueológica. Según esto las sociedades tribales o pre-estatales no son sociedades políticas sino pre-políticas. Gustavo Bueno, en una de sus obras, comparó los Estados con las biocenosis que estudian los biólogos: en los Estados habría un conjunto de grupos muy heterogéneos enfrentados unos con otros, lo mismo que en las biocenosis se enfrentan entre sí diversos grupos de organismos ${ }^{4}$. La virtud política fundamental, aquella que debe tener el buen mandatario, es la de conservar el Estado: lograr que sea más seguro, que esté más unido, mejor estructurado, y que sea más fuerte y con más capacidad de actuar en el ámbito internacional. El buen mandatario político recibe el Estado en una situación dada y tiene que lograr que, a lo largo de su gobierno, el Estado se conserve y mejore en su seguridad interior y exterior, en su unión y cohesión interna, en su riqueza económica y su poder geoestratégico, y consiga estar más preparado para hacer frente a las amenazas que vienen de dentro y de fuera. El mal mandatario,

$3 \quad$ WAAL, F., La política de los chimpancés. Madrid: Alianza, 1982.

4 Bueno, G., Primer ensayo sobre las categorías de las ciencias políticas, Logroño, Cultural Rioja, 1991. http://www.fgbueno.es/gbm/gb91ccp.htm 
aquel que traiciona sus funciones, por el contrario, es aquel que devuelve el Estado roto, hecho jirones, inestable, débil, hipotecado, sin presencia ni importancia en el ámbito internacional, exhausto, dependiente, con su soberanía amenazada, expuesto a la voluntad de sus enemigos internos y externos. El gobernante de un Estado no ocupa ese puesto para lograr la paz mundial ni la concordia universal, ni para lograr la mejoría de los Estados vecinos, sino para que mejore su Estado y gane en potencia de obrar, en soberanía, en fortaleza y en seguridad. Spinoza caracteriza del siguiente modo el Estado bien constituido:

Cuál sea la mejor constitución de un Estado cualquiera se deduce fácilmente del fin del Estado político que no es otro que la paz y la seguridad de la vida. Aquel Estado es, por tanto, el mejor, en el que los hombres viven en concordia y en el que los derechos comunes se mantienen ilesos. Ya que no cabe duda que las sediciones, las guerras y el desprecio o infracción de las leyes no deben ser imputados tanto a la malicia de los súbditos cuanto a la mala constitución del Estado [...] Efectivamente, un Estado político que no ha eliminado los motivos de sedición y en el que la guerra es una amenaza continua y las leyes, en fin, son con frecuencia violadas, no difiere mucho del mismo estado natural, en el que cada uno vive según su propio sentir y con gran peligro de su vida. ${ }^{5}$

Y, en otro lugar del Tratado político, dice Spinoza "En efecto, la libertad de espíritu o fortaleza es una virtud privada [diríamos nosotros, individual, "ética”],

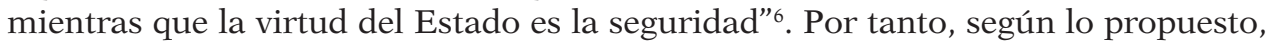
de un lado están las normas éticas que regulan la marcha del sujeto individual, y, por otra parte, están las normas políticas que son aquellas a las que tiene que atenerse el gobernante (con independencia del procedimiento que se haya utilizado para su elección) para velar por la buena marcha del Estado, por su seguridad, por su unidad, por su cohesión interna, y por su crecimiento pues esa es la tarea en la el mandatario tiene que poner su empeño.

\section{SOBRE LA INCOMPATIBILIDAD ESTRUCTURAL ENTRE ÉTICA Y POLÍTICA EN GENERAL}

Una vez aclarado lo que voy a entender por ética y por política en el contexto de este artículo, pasaré a analizar dos ejemplos de incompatibilidad estructural entre estos dos ámbitos. Desde cierto fundamentalismo ético, existe una tendencia a considerar que el asunto de las relaciones entre ética y política es muy sencillo porque se postula que la política tiene que estar siempre subordinada a la ética. De este modo, las leyes éticas tendrían que respetarse siempre pues el Estado tendría que estar al servicio de la ética, al servicio de los sujetos individuales y de sus necesidades. Yo voy a defender aquí que esta idea no se corresponde con lo que sabemos acerca de los Estados realmente existentes (tanto históricos como actuales), y que existen razones estructurales para que esto sea sí.

En el ámbito del derecho, y hablando en general, se suele entender que los delitos contra la propiedad son más leves que los delitos contra la integridad física de las

5 SPINOZA, B., op.cit., V, §2.

6 SpINozA, B., op.cit., I, §6. 
personas, y así lo contemplan la mayor parte de los ordenamientos jurídicos de los países de nuestro entorno: por ejemplo, se considera más grave matar, mutilar, o violar que robar. Efectivamente, hay razones serias para considerar que los delitos contra la propiedad, en la medida en que ésta es separable del sujeto corpóreo individual, son menos graves que aquellos otros cometidos contra la integridad del sujeto corpóreo mismo. Por esta razón, los problemas más graves cuando se considera la colisión entre política y ética se dan cuando, por razones políticas, se atenta contra la integridad física de los individuos corpóreos humanos o contra su integridad personal: contra su vida, contra su salud, contra su seguridad, o contra su honor.

Un caso límite, pero frecuente, es el caso de la guerra: cuando el Estado se ve involucrado en una guerra defensiva, sabe que sus nacionales morirán en el combate, pero ese mal ético (la muerte y la mutilación de personas inocentes) se considera necesario para lograr un bien político (la defensa del Estado), y esto por no hablar de los muertos infligidos en el bando contrario que también son individuos humanos. Quisiera hacer notar que, a estos efectos, da lo mismo que el Estado que lanza las bombas sea un Estado democrático o no lo sea: democrático fue el Estado que lanzó dos bombas atómicas contra la población civil indefensa en Hiroshima y Nagasaki. En este caso, los requerimientos políticos pasan por encima de los éticos, y se considera un honor (moral y político) el sacrificio que los soldados hacen por el bien de su Estado cuando reciben el tratamiento de héroes. Sería puro idealismo histórico pensar que ya hemos alcanzado la situación de la Paz Perpetua de Kant y suponer que las guerras fueran una cosa del pasado pues los conflictos armados han ocurrido en el pasado desde los orígenes de los estados prístinos, ocurren en el presente y, con el permiso de Kant, no hay ningún indicio racional para suponer que vayan a dejar de ocurrir en el futuro. Aunque Kant parecía saber de buena tinta que esto no sería así en el futuro, no llegó a hacernos partícipes de las fuentes de su evidencia ${ }^{7}$. La guerra, como "continuación de la política por otros medios" (usando la acertada fórmula de Clausewitz ${ }^{8}$ ), es siempre el modo último de resolver los conflictos entre los Estados políticos y conlleva de un modo estructural la muerte de individuos humanos. Los ejércitos han sido siempre partes constitutivas irrenunciables de los Estados desde sus inicios, ya que un Estado que carezca de ejército tendrá siempre su independencia y su soberanía nacional subrogadas.

Otro ejemplo de actualidad que muestra la colisión entre la ética y la política lo tenemos a propósito del control de las fronteras que todos los Estados tienen que realizar si no quieren que su propia viabilidad se vea puesta en peligro. Si nos instaláramos en una perspectiva puramente ética, todas las personas por igual deberían tener los mismos derechos para circular libremente por el planeta y para establecerse donde mejor les pareciera, pero, de hecho, la libertad de circulación y de residencia es muy diferente según se sea ciudadano de uno u otro Estado: las alambradas, las patrulleras, la policía, y las deportaciones condenan a millones de personas a vivir en situaciones inhumanas en sus países de origen, y a esclavizarse

$7 \quad$ Kant, I., Sobre la paz perpetua, 1795.

8 Clausewitz, C. von, De la guerra, OP escrito en el periodo 1818-1830. 
y prostituirse, o directamente a morir, intentando entrar en un Estado que les permita vivir con cierta dignidad. En la agenda política de los Estados asediados por esta inmigración está ya, de un modo explícito, la estrategia de ayudar a los países de donde procede esa marea humana a cambio de que sean ellos mismos los que cierren sus propias fronteras e impidan la salida de los desposeídos, de modo que el problema quede alejado de las sociedades del bienestar que no desean ver niños ahogados yaciendo en sus playas. Este enfrentamiento entre ética y política, en este caso, como en el caso de la guerra, es estructural: si uno de esos Estados del bienestar abriera de par en par sus fronteras en virtud de un tratamiento igualitario hacia todas las personas y de una generosidad ética universal, se pondría en riesgo ese Estado y el bienestar de sus nacionales. El Estado quedaría invadido por pueblos con otras culturas, otras lenguas y otras religiones, colapsaría el sistema de seguridad social, de pensiones, de cobertura sanitaria y de educación, y se destruiría su estabilidad interna. Se pueden discutir muchos asuntos relativos al mejor modo de gestionar las fronteras pero, en último término, toda nación tiene que tener unas fronteras puesto que el Estado implica, desde sus inicios, la apropiación de un determinado territorio por parte de una población dada. También en este ejemplo se aprecia que es una cuestión de hecho que las naciones priman su viabilidad política frente a lo que serían los requerimientos de la generosidad ética universal, y están dispuestos a sacrificar la vida y los intereses más básicos de millones de personas con tal de conservar su buena marcha. Los argumentos expuestos sugieren que este proceder anti-ético puede considerarse estructural ya que, de no llevarse a cabo esa política restrictiva, la viabilidad del Estado anfitrión quedaría comprometida, y también sugieren que esta contradicción entre requerimientos éticos y viabilidad política afecta a todos los estados con independencia del procedimiento por el que se elijan sus dirigentes.

Aunque se podrían poner otros ejemplos, sirvan estos dos para ilustrar el modo cómo los mandatos éticos colisionan con los políticos, y para mostrar, con hechos y con argumentos generales más abstractos, las razones por las que hemos afirmado hace un momento que la política no está siempre, ni pueda llegar a estar, subordinada a la ética. Si la política estuviese siempre regida por la ética los Estados serían inviables: ni habrían aparecido los estados prístinos ni existirían los estados actuales. Quiero reiterar una vez más que mi intención en este artículo no es hacer una condena ética en nombre de Dios, del pueblo o de la Historia de un determinado estado de cosas, ni mucho menos hacer una apología de la violencia inherente a las guerras y a los procedimientos policiales de control de las fronteras, sino analizar la estructura de un problema objetivo de modo que esas políticas antiéticas no sean vistas tanto como vicios de un gobernante malvado que se regocija con el dolor ajeno, sino como contenidos inherentes a la propia naturaleza del Estado, como políticas que son necesarias para que el Estado mismo exista.

El planteamiento explícito de este conflicto entre ética y política conduce al reconocimiento de situaciones tan duras y tan desalmadas que los propios Estados movilizan todos los recursos lenitivos a su alcance para disimular ese conflicto y tranquilizar a la opinión pública, procedimientos entre los que están todo tipo de mitos irenistas y de quiliasmos soteriológicos.

A la vista de estos ejemplos, la idea de que la política debe estar siempre subordinada a la ética o bien es un desideratum o, de otra forma, habría que 
considerarla como una idea propia de una concepción idealista del Estado político que es incapaz de entender que la custodia de un territorio previamente apropiado es condición sine qua non de cualquier Estado realmente existente.

Quisiera añadir una consideración más acerca de las relaciones entre la ética (o, en este caso, la moral) y la política en otro momento histórico ya que estas relaciones no siempre tuvieron la morfología que presentan en la actualidad: en la Edad Media europea, y en los inicios de la Edad Moderna, se consideraba que el poder de los reyes de los Estados católicos venía de Dios y, por tanto, el rey católico, en ciertos asuntos de Estado, estaba obligado por la moral teológica católica: por ejemplo, tenía prohibido pactar con los protestantes o con los musulmanes para ir en contra de otro reino católico porque se entendía que esa política iba contra el propio Dios. En el límite, algunos de los proyectos políticos del rey católico estaban guiados por el mandato religioso de hacer llegar el Evangelio a todos los rincones del mundo: este fue el proyecto del imperio español cuando cristianizó y convirtió a los nativos americanos en ciudadanos españoles católicos. La moral católica era concebida como universal y, por tanto, desde un punto de vista emic, era entendida como algo parecido a lo que nosotros conocemos hoy como "ética". Fernando II de Habsburgo, por ejemplo, en coherencia con su moral católica, suprimió el protestantismo en los territorios que estaban bajo su mandato lo que precipitó la llamada "Guerra de los Treinta Años" (1616-1646). En 1629, en vez de detener la guerra y buscar un pacto, promulgó el Edicto de Restitución para devolver a los católicos las propiedades eclesiásticas secularizadas desde la paz de Passau. El Príncipe de Maquiavelo, publicado en 1513, pasa por ser la primera obra moderna en la que el fin político se pone por delante del bien ético (o moral) de un modo muy explícito. Eso le valió a Maquiavelo la circunstancia de que su propio apellido diera lugar al sustantivo "maquiavelismo" que suele ir acompañado de connotaciones peyorativas. Dice Maquiavelo:

Y hay que tener bien en cuenta que el príncipe, y máxime uno nuevo, no puede observar todo lo que hace que los hombres sean tenidos por buenos, ya que a menudo se ve forzado, para conservar el Estado, a obrar contra la fe, contra la caridad, contra la humanidad, contra la religión. Por eso tiene que contar con ánimo dispuesto a moverse según los vientos de la fortuna y la variación de las circunstancias se lo exijan, y como ya dije antes, no alejarse del bien, si es posible, pero sabiendo entrar en el mal si es necesario. [... $]^{9}$

Y aquí se debe señalar que el odio se gana tanto con las buenas como con las malas obras; así que, como ya dije antes, un príncipe que quiera mantener su Estado se ve a menudo forzado a no ser bueno porque, cuando aquella colectividad, ya sean pueblos soldados o grandes señores, que tú juzgues necesaria para mantenerte, esté corrompida, te conviene seguir su humor para satisfacerla, con lo que, entonces, las buenas obras son tus enemigas ${ }^{10}$.

Así pues, el político que no sabe hacer el mal ético "si es necesario" no puede ser un buen político porque, a veces, el Estado requiere el mal ético. El cardenal católico francés Richelieu, enfrentado a Fernando II en la citada Guerra de los Treinta Años, pasa por ser el primero que, de un modo explícito, justificó la separación

\footnotetext{
9 Maquiavelo, N, El príncipe, XVIII.

10 Maquiavelo, N, op.cit., XIX.
} 
de la moral católica frente a la praxis política del Estado francés, llevando a la práctica la idea expuesta por Maquiavelo en El príncipe, resumida en la famosa fórmula de la "raison d'état" (que los ingleses tradujeron por "national interest"). Para Richelieu, la razón de Estado, los intereses del Estado francés, estaban por encima de cualquier otra consideración, estaban por encima incluso de cualquier norma moral o religiosa, lo que le permitió aliarse con otomanos y protestantes en contra del rey católico Fernando II, incluso siendo Richelieu, como era, un príncipe de la iglesia católica. A partir de ese momento, en la política internacional europea, la moral religiosa asociada a la teoría del origen divino del poder pasó a un segundo plano eclipsada por el interés del propio Estado, de esos Estados que luego se convertirían progresivamente en naciones en sentido moderno. La teoría política según la cual los Estados son los actores políticos más importantes sobre los que no existe ningún poder ni norma superior que regule sus relaciones (al margen de los tratados que ellos mismos, en el ejercicio de su soberanía, decidan asumir) es lo que se conoce como "realismo político"; la práctica política asociada a esa teoría es la llamada "Realpolitik", término alemán acuñado por Ludwig von Rochau en su conocido libro Principios de Realpolitik ${ }^{11}$. Por supuesto, con esto no estoy intentando decir que en la Edad Media no hubiera conflictos o tensiones entre lo que ahora llamamos requerimientos éticos y la realidad política pero, como digo, algunos de estos conflictos tenían una morfología diferente en la que la moral religiosa jugaba un papel importante pues el papa estaba ungido por Dios y, por tanto, tenía un estatus especial. La Edad Moderna y la ulterior caída del Antiguo Régimen se suele caracterizar por la pérdida relativa del poder moderador político por parte de la iglesia católica, un poder político que, en la escolástica medieval y moderna, forma parte de un sistema teológico y antropológico en el que los principios morales católicos tienen una papel cardinal (como lo tuvieron en el derecho de gentes).

En el mundo sin Dios posterior a la Revolución Francesa, la moral y la política religiosa dejan paso a la Realpolitik: ya no es posible apelar a una ética o una moral dadas por Dios que estén por encima del Estado y de la política. Muchos juzgarán esta situación como aberrante, pero deberían recordar que, desde una antropología no teológica, el sujeto individual personal, su libertad, su seguridad, la igualdad, su educación y, en general, su constitución como ciudadano y como persona, sería imposible fuera del Estado. Los derechos que un ciudadano europeo tiene y que salvaguardan su integridad personal no los tiene en cuanto que ciudadano del mundo sino en cuanto inglés, francés, o español. Tiene que haber un Estado que haga valer esos derechos pues hay muchos lugares del mundo en los que esos mismos derechos no significan nada, donde no existen. Si en ciertos lugares se respetan es gracias a un determinado Estado y si ese Estado deja de existir entonces inmediatamente dejan de existir esos derechos y la ética que está detrás de esos derechos. Esa ética es ella misma también una construcción histórica dentro de un Estado realmente existente. Una vez que el poder supraterrenal moderador ha dejado de existir, es la propia confrontación entre los Estados la que determina el poder relativo de cada uno con respecto a los demás, y el poder y la soberanía de

11 Rochau, L. von, Grundsätze der Realpolitik, Stuttgart, Göpel, 1853. 
algunos Estados para hacer valer ciertos principios éticos dentro de sus fronteras y en el trato recibido por sus nacionales en el exterior.

\section{LA IDENTIDAD CULTURAL E HISTÓRICA DE CIERTOS EsTADOS COMO JUSTIFICACIÓN DE LA VIOLACIÓN DE LOS PRINCIPIOS ÉTICOS}

Los principios éticos que salvaguardan la integridad del individuo humano y que presuponen la igualdad distributiva entre las personas, a pesar de estar construidos como principios universales en cuanto a su esencia, sin embargo no son universales en cuanto a su implantación práctica política, en cuanto a su existencia. No me refiero ahora a la incompatibilidad inevitable entre ética y política exigida por la misma viabilidad de todo Estado y que he considerado en el epígrafe anterior, ni se trata tampoco de considerar la eventualidad de que alguna persona particular actúe de un modo antiético pues esto podrá ocurrir en cualquier Estado ya que es imposible erradicar por completo los asesinatos, los asaltos violentos, las violaciones y tantas otras conductas delictivas que atentan contra la individualidad física y moral de las personas. Lo que quiero tratar en este epígrafe es la existencia de Estados que, amparándose en su identidad histórica o cultural, permiten o incluso promueven conductas antiéticas institucionalizadas que, en principio, podrían evitarse.

Este es el caso de aquellos Estados en los que está tolerada la mutilación genital pues toda mutilación es una violación grave de la integridad física individual. Nuestros conocimientos médicos confirman sin ningún género de dudas el carácter dañino y perjudicial de esas prácticas y su absoluta falta de justificación. Otro caso frecuente de violación institucionalizada de las normas éticas más básicas es el de las restricciones graves y gratuitas que sufren las mujeres en muchos Estados: limitaciones en la libertad de movimientos, y en el acceso al estudio, al trabajo y a multitud de actividades públicas y privadas. Todas estas restricciones atentan contra el desarrollo personal de esas mujeres y, por tanto, socavan su firmeza y su fortaleza pues las convierten en personas de segunda categoría sin posibilidad alguna de redención. Ciertas restricciones severas en los hábitos del vestir de las mujeres también cumplen esta función de sometimiento a los hombres y de afirmación de lo que los antropólogos llaman un "complejo de supremacía masculina".

Por supuesto, hay que citar también aquí los Estados que tienen institucionalizada la tortura o la toleran de un modo sistemático. Por otra parte, es universalmente admitido en todos los Estados que ciertos delitos graves deben llevar asociada una pena de privación de libertad. Esa pena tiene muchas funciones no siendo la menor la de permitir al reo redimir su falta ante la sociedad, y redirigirle hacia la conducta correcta para integrarle en la sociedad como un ciudadano más. Suele entenderse que esa restricción temporal de la libertad tiene una clara intención ética pues cumple esa función correctora y rehabilitadora. Sin embargo, la función redentora, "elevante", de las condenas desaparece cuando nos referimos a la mal llamada "pena de muerte". La expresión "pena de muerte" es casi un oxímoron ya que el penado no puede sufrir pena alguna si es que se le mata. Por esta razón, Gustavo Bueno propone que se designe como "eutanasia procesal", es decir, una muerte producida adrede de un modo piadoso como consecuencia de un proceso judicial justo, y que estaría reservada para los convictos y confesos de crímenes horrendos en los que resultaría 
repugnante pensar siquiera en la posibilidad de una redención y rehabilitación del criminal $^{12}$. Lo mismo que los médicos pueden desahuciar a un enfermo terminal y evitar el ensañamiento terapéutico, se diría que un Estado podría desahuciar a ciertos autores de crímenes horrendos, al considerarlos como una especie de "enfermos éticos incurables", promoviendo su eliminación eutanásica. Gustavo Bueno mantiene que el Estado no cometería crimen ético alguno puesto que el reo habría dejado de ser persona y resultaría irrecuperable. Esa supuesta despersonalización total es, sin embargo, muy controvertida, lo que lleva a pensar que la eutanasia procesal en tiempo de paz implica atentar directamente contra la vida de una persona (por patológica que sea o desintegrada que esté), y que entonces supone un acto antiético institucionalizado y no necesario. La pena de muerte en tiempo de guerra tiene un significado distinto pues, como ha quedado expuesto en el epígrafe anterior, el crimen ético se reconoce de modo explícito aunque se le da una justificación política.

\section{4. Ética y POLÍTICA EN SITUACIONES EN LAS QUE NO HAY CONTRADICCIÓN}

Me he referido a dos situaciones (las guerras y las políticas de fronteras) en las que cualquier Estado, si quiere conservarse en el ser, tiene que sacrificar el bien ético para lograr su supervivencia como Estado político. He mencionado después la existencia de estados particulares que, en virtud de su estructura idiosincrática conculcan sistemáticamente principios éticos apelando a su identidad histórica o cultural. Sin embargo, la buena marcha de un Estado realmente existente, en muchas circunstancias, no colisiona con los principios de la ética, e incluso, en ocasiones, el Estado persigue, también por motivos estructurales, los mismos objetivos que la ética: al Estado le interesa que sus ciudadanos estén sanos y tengan una formación cualificada pues eso, en general, contribuye a la buena marcha de la nación, a su fortaleza y a su seguridad; en todo caso, ese mismo Estado debe velar por los contenidos de esa educación pues sería suicida que se dedicase a promover la formación de terroristas o de traidores y sediciosos que atentaran luego contra su propia seguridad.

Hay otros asuntos en los que la política se desentiende de las normas éticas que velan por la firmeza de las personas: así, por ejemplo, las prácticas de fumar, abusar de la bebida y de las drogas o tener una conducta excesivamente promiscua pueden ser perjudiciales para la salud del individuo si es que ponen en riesgo su firmeza y, sin embargo, muchos Estados evitan censurarlas. Unas veces la pasividad del Estado se justifica por la imposibilidad de controlar efectivamente ciertas conductas, otras por el carácter contraproducente de su persecución (como ocurrió con la ley seca), y otras, en fin, apelando a la doctrina según la cual el Estado no debe entrometerse en cuestiones que se consideran íntimas o propias de la vida privada. Desde la concepción de la ética bosquejada en el epígrafe primero de este artículo, el aborto provocado de embriones humanos sanos implantados es censurable ya que significa matar a un individuo humano en sus fases tempranas

12 Bueno, G., Panfleto contra la democracia realmente existente, Madrid, La esfera de los libros, 2004. 
de formación. Sin embargo, la oportunidad política de las leyes restrictivas en materia de aborto es un asunto que se discute con otros argumentos: por una parte, con las tecnologías médicas actuales, y en el contexto de un tráfico internacional generalizado de personas, el aborto temprano resulta casi imposible de perseguir $\mathrm{y}$, por otra parte, hay estudios que sugieren que las legislaciones restrictivas en esta materia no hacen disminuir las tasas de aborto. ${ }^{13}$ No obstante, la circunstancia de que, desde las administraciones, se trate de reducir algunas de las prácticas referidas en este párrafo, utilizando, por ejemplo campañas de información y propaganda, probablemente se justifica porque el Estado las considera dañinas para el individuo y, por tanto, desde nuestras coordenadas, antiéticas.

También se dan situaciones en las que una conducta punible es neutral desde el punto de vista ético y, sin embargo, es censurable desde un punto de vista político: la conculcación de las leyes que regulan la imposición tributaria suele ser, en principio, éticamente neutra (pues no atenta de un modo inmediato contra la firmeza o fortaleza de otra persona) pero tiene un significado político muy claro ya que, puesto que los tributos contribuyen directamente al sostenimiento del Estado, el que defrauda al Estado está cometiendo un crimen político. A los efectos de las situaciones consideradas hasta el momento en este epígrafe la cuestión de las formas de gobierno de cada Estado puede considerarse accidental.

Un caso sujeto a muchas contingencias y con una estructura más compleja es el de la llamada corrupción política. Si el lector sigue acompañándome en el uso de los modos de caracterizar la ética y la política que he introducido en el apartado primero de este trabajo, entonces se debería admitir que la corrupción política es un mal que puede ir acompañado de valores negativos, éticos y políticos a la vez. Desde luego, es un mal eminentemente político si se están robando directamente los bienes del Estado, y es también un mal político en la medida en que desprestigia las instituciones de gobierno y socava su credibilidad induciendo inestabilidad política. Pero también puede ser un mal ético cuando utiliza la extorsión y la mentira pues éstas afectan directamente a la firmeza de las personas particulares implicadas, sin importar a estos efectos si esas otras personas aceptan la extorsión de un modo voluntario ya que, aunque así fuera, su firmeza no dejaría por ello de quedar igualmente comprometida.

Universidad de Oviedo

David AlvargonzÁlez

Departamento de Filosofía

dalvar@uniovi.es

[Artículo aprobado para publicación en diciembre de 2016]

13 Alvargonzález, D., «The constitution of the human embryo as substantial change», Journal of Medicine and Philosophy, 2016. doi:10.1093/jmp/jhv062

http://www.ncbi.nlm.nih.gov/pubmed/26850033

Alvargonzález, D., «Towards a non-ethics-based consensual public policy on abortion», International Journal of Health Planning and Management, 2015.

doi: 10.1002/hpm.2320

http://onlinelibrary.wiley.com/doi/10.1002/hpm.2320/abstract;jsessionid=56A06F306DDC DE0B88C708F3ACA2DE21.f03t01? userIsAuthenticated=false\&deniedAccessCustomisedMes sage $=$ 